\title{
SISTEMA DE MONITORAÇÃO DAS VENTANEIRAS DO ALTO FORNO $3^{*}$
}

\section{Resumo}

Moacir Alves dos Reis ${ }^{1}$ Vanderson Machado de Oliveira ${ }^{2}$ Flávio Lopes Machado da Silva ${ }^{3}$ Aurélio Duque Bastos ${ }^{4}$

A fim de monitorar visualmente as condições de funcionamento em cada ventaneira do alto-forno 3, foi instalado um sistema de monitoração através de câmeras especiais de vídeo em cada ventaneira permitindo assim a inspeção visual para verificar as condições das ventaneiras. A inspeção na ventaneira é de particular importância quando carvão pulverizado é injetado através da mesma. Caso ocorra um bloqueio na injeção de uma ventaneira, o carvão pulverizado pode queimar no tubo reto ao invés de queimar no alto forno, resultando assim em danos consideráveis para o tubo reto, ocasionando também a parada do Alto Forno. Por segurança, o fornecimento de carvão pulverizado para uma ventaneira dever ser interrompida assim que for detectado o bloqueio. $O$ bloqueio pode ser detectado tanto por olhando diretamente para a ventaneira através do visor ou continuamente através do sistema de monitoração.Principais facilidades deste sistema: Monitoração contínua das condições operacionais das ventaneiras e do Alto Forno; Monitoração visual e eletrônica simultaneamente; Totalmente isolado da pressão do Alto Forno; Fácil de ajustar; Fabricação especial para trabalhar em áreas agressivas; e Fácil adaptação nas ventaneiras existentes em um Alto Forno.

Palavras-chave: Ventaneiras; Câmera; Alto Forno.

\section{Abstract \\ MONITORING SYSTEM OF THE BLAST FURNACE 3 TUYERES}

In order to view the operating conditions in each blast furnace \#3 tuyères, a monitoring system was installed through special video cameras in each tuyères allowing visual inspection to check the tuyères condition. The inspection of the tuyères is of particular importance when pulverized coal is injected through itself. If there is a blockage in the injection of a tuyères the pulverized coal can burn into the straight pipe instead of into the Blast Furnace, resulting in considerable damage to the straight pipe, and causing the Blast Furnace shutdown. For safety reasons, the supply of pulverized coal into a tuyères should be interrupted as soon as the blockage is detected. The blockage can be detected either by looking directly at the tuyères through the viewfinder or continuously through the monitoring system. Main features of this system: Continuous monitoring of the operating conditions of the tuyères and Blast Furnace; Visual and electronic simultaneous monitoring; Fully isolated from the blast furnace pressure; Easy to adjust; Special Design to work in hard conditions areas; and Easy adaptation to existing tuyères in the Blast Furnaces \#2 and \#3.

Keywords: Tuyères; Cameras; Blast Furnace.

\footnotetext{
Senior Engineer, CSN, Volta Redonda, RJ, Brasil.

Production Engineer, CSN, Volta Redonda, RJ, Brasil.

Specialist Engineer, CSN, Volta Redonda, RJ, Brasil.

Technical Specialist, CSN, Volta Redonda, RJ, Brasil.
} 


\section{INTRODUÇÃO}

O Alto Forno é um reator metalúrgico de contra corrente, com a carga descendo e os gases $(\mathrm{CO}$ e $\mathrm{CO} 2$ ) subindo oriundos da queima do combustível nas ventaneiras que sopram ar aquecido a $1000^{\circ} \mathrm{C}$ ou mais.

O Alto Forno é tecnicamente dividido em regiões ou zonas. Na região das ventaneiras o oxigênio $(\mathrm{O} 2)$ que corresponde a $21 \%$ do ar quente que é soprado no interior da zona de combustão, queima o carbono do coque ou carvão vegetal, gerando CO2. Este gás $\mathrm{CO} 2$ reagirá com mais carbono enquanto a temperatura for superior a $900^{\circ} \mathrm{C}$ na chamada zona de reserva térmica gerando $\mathrm{CO}$ (monóxido de carbono).

Essa reação que é uma das mais importantes do Alto Forno é chamada de regeneração do $\mathrm{CO} 2$ pode ser assim representada: $\mathrm{CO} 2+\mathrm{C}=2 \mathrm{CO}$

Esse $\mathrm{CO}$ é um gás redutor capaz de reagir com o oxigênio dos óxidos de ferro presentes, gerando $\mathrm{CO} 2$ (dióxido de carbono) e liberando o Ferro que é depositado no Cadinho na forma líquida e é chamado de Ferro Gusa.

A Escória,que é oriunda das chamadas impurezas que estão presentes na carga, tais como os óxidos de Silício (SiO2), óxido de Alumínio (Al2O3), óxido de cálcio (Cao)e óxido de magnésio (MgO), são derretidas na região inferior do Alto Forno (Rampa) devido a altas temperaturas reinantes, e quimicamente combinadas em quantidades dosadas através das correções feitas com os Fundentes. Isso confere à Escória a necessária fluidez para permitir seu escoamento para fora do Cadinho do Alto Forno.

É importante ressaltar que no Cadinho do Alto Forno, Gusa e Escória ocupam os vazios deixados pelo coque. A Escória por ser mais leve fica por cima do Gusa que é mais denso. A figura 1 ilustra a sistema descrito anteriormente.

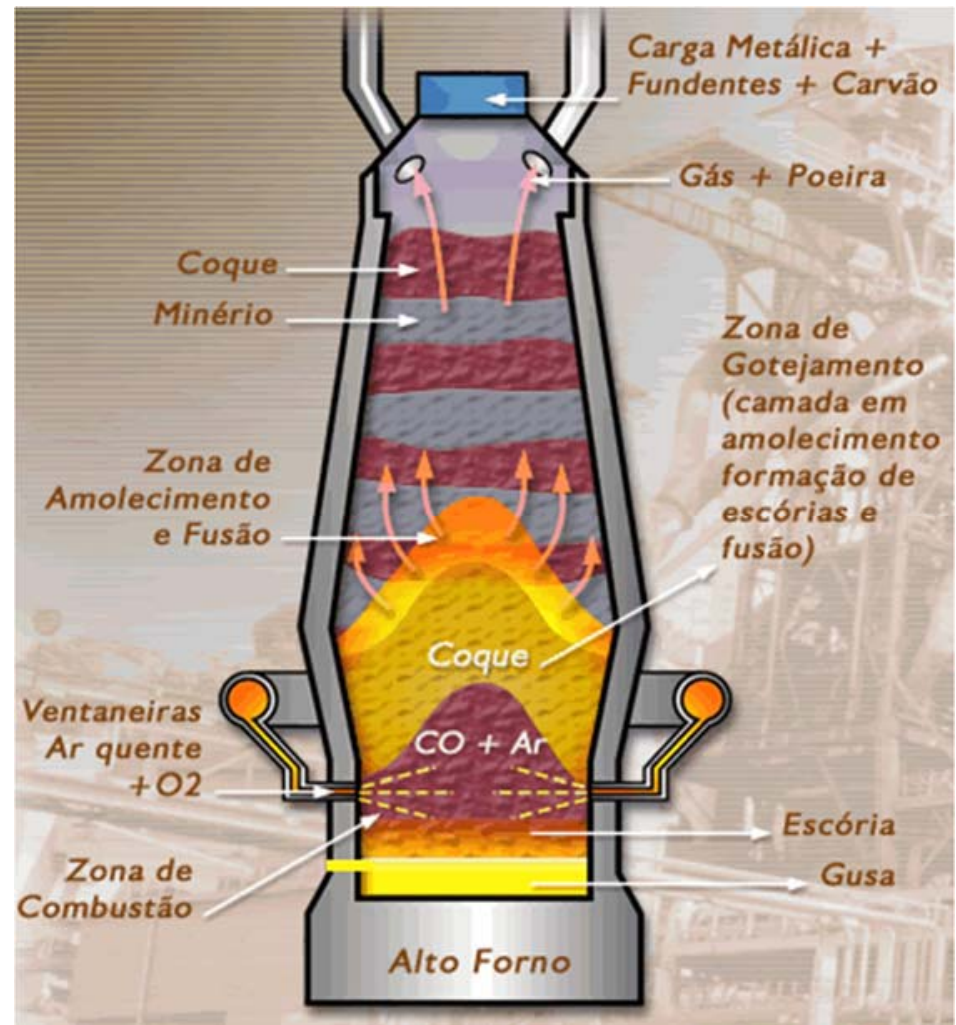

Figura 1 - Processo de Redução de um Alto Forno 


\section{FUNÇÃO DAS VENTANEIRAS}

São peças de cobre refrigeradas com água, que penetram até $500 \mathrm{~mm}$ no interior do forno, e por isso são submetidas a altas temperaturas e abrasão dos materiais no interior do forno. Posicionadas na parte superior do cadinho, tem a função de direcionar o ar quente que é soprado no forno para estimular a queima do carvão, de forma uniforme ao redor do forno. A quantidade de ventaneiras em um forno irá depender o diâmetro do cadinho, podendo em grandes Altos Fornos chegar a 40 ventaneiras e em pequenos fornos somente 6 . A inspeção na ventaneira é de particular importância quando carvão pulverizado é injetado através da mesma. Caso ocorra um bloqueio na injeção de uma ventaneira, o carvão pulverizado pode queimar no tubo reto ao invés de queimar no alto forno, resultando assim em danos consideráveis para o tubo reto, ocasionando também a parada do Alto Forno. Por segurança, o fornecimento de carvão pulverizado para uma ventaneira dever ser interrompida assim que for detectado o bloqueio. O bloqueio pode ser detectado tanto olhando diretamente para a ventaneira através do visor, através do granuflow ou através de um sistema de monitoração. As figuras 2 e 3 ilustram este processo.

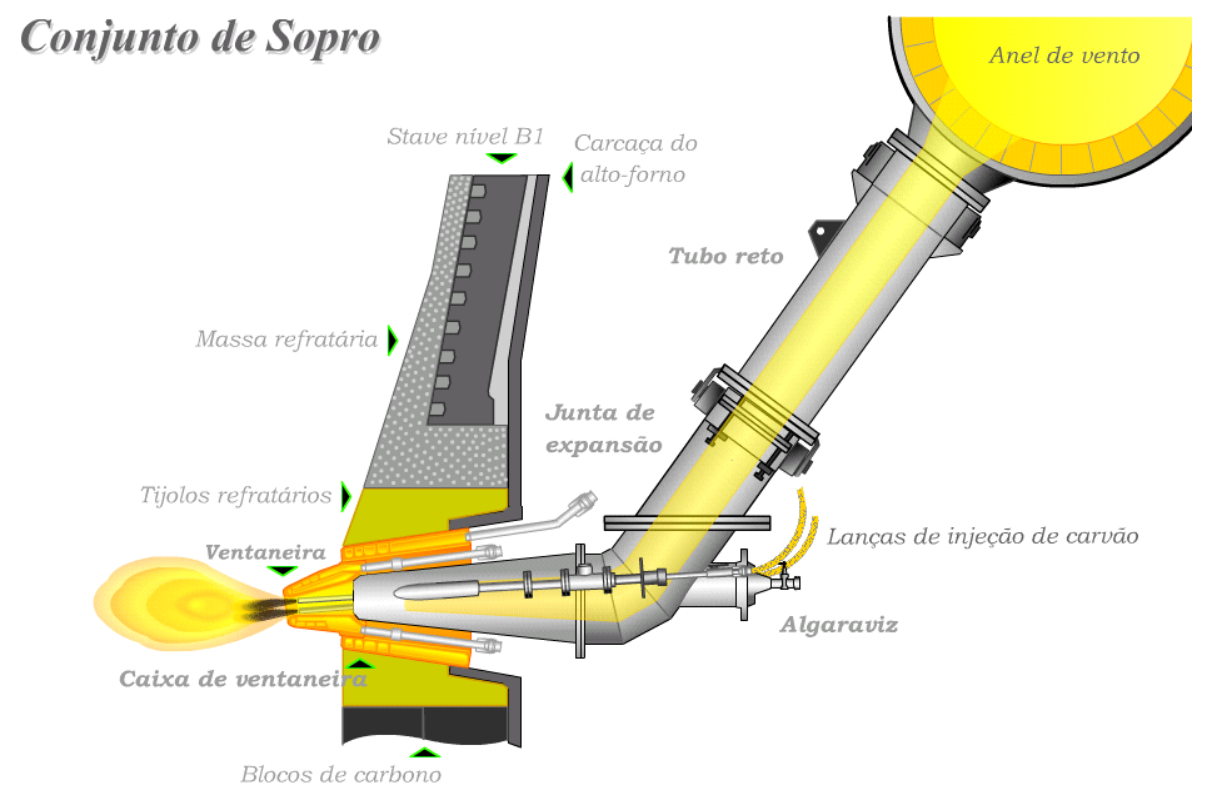

Figura 2 - Conjunto de Sopro composto de ventaneira, algaraviz e tubo reto.

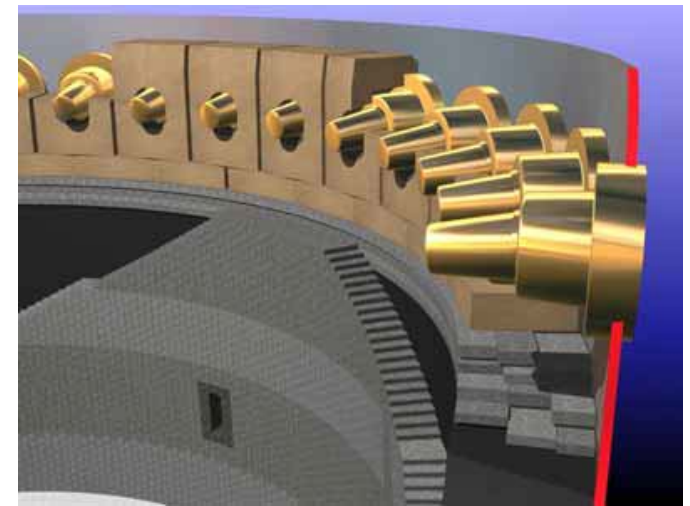

Figura 3 - Disposição das ventaneiras no interior de um Alto Forno. 


\section{PROJETO DO SISTEMA DE MONITORAÇÃO DAS VENTANEIRAS DO ALTO FORNO 3}

\subsection{Tomada de Decisão}

- Implantamos uma tecnologia nova na América Latina para a monitoração online das ventaneiras;

- Evitar exposição dos operadores no piso das ventaneiras;

- Acidente ocorrido em 2008 com o Algaraviz devido a obstrução do carvão injetado;

- Dificuldade para identificar problemas de injeção nas ventaneiras.

\subsection{Objetivos}

- Produzir uma ferramenta que auxilie no processo de monitoração da injeção de carvão pulverizado das ventaneiras em tempo real;

- Reduzir as inspeções in loco de 38 ventaneiras;

- Evitar ocorrências de parada de emergência do Alto Forno devido a entupimento do Algaraviz;

- Criar outras ferramentas para acompanhamento do processo do Alto Forno;

- Aumentar o moral dos operadores.

\subsection{Cronograma Macro}

\begin{tabular}{|c|c|c|c|c|c|c|}
\hline \multirow[b]{2}{*}{ O QUE } & \multicolumn{6}{|c|}{ ANO } \\
\hline & 2009 & 2010 & 2011 & 2012 & 2013 & 2014 \\
\hline $\begin{array}{l}\text { Estudar e contactar firmas que } \\
\text { trabalham com a tecnologia de } \\
\text { monitoração on-line nas ventaneiras }\end{array}$ & & & & & & \\
\hline $\begin{array}{l}\text { Desenvolver a tecnologia com a firma } \\
\text { Infratemp no Brasil }\end{array}$ & & & & & & \\
\hline $\begin{array}{l}\text { Montar e ajustar o equipamento na } \\
\text { ventaneira } 7\end{array}$ & & & & & & \\
\hline $\begin{array}{l}\text { Testar o equipamento para verificar a } \\
\text { performance na sala de controle do } \\
\text { Alto Forno } 3\end{array}$ & & & & & & \\
\hline $\begin{array}{l}\text { Emitir RC para a compra do Sistema } \\
\text { de monitoração do AF3 }\end{array}$ & & & & & & \\
\hline $\begin{array}{l}\text { Implantar todo o projeto de } \\
\text { monitoração no Alto Forno } 3\end{array}$ & & & & & & \\
\hline
\end{tabular}

\subsection{Solução Adotada}

Um novo sistema de monitoração através de câmeras de vídeo foram instalados em 38 ventaneiras no Alto Forno 3 . Os sinais de vídeo que vem das câmeras são multiplexados e transmitidos para os computadores da sala de controle. Todas as ventaneiras são visualizadas através de monitores de vídeo instalados na sala de controle e casa de corridas. Os operadores podem visualizar através dos monitores de vídeo a situação de cada ventaneira, como injeção ou não de carvão, cascão, entupimento, etc. Estas informações servem como importante referência para a 
operação do alto forno. Todas as imagens são gravadas e analisadas no sistema para gerarem alarmes e gráficos para avaliações on-line ou posteriores.

\section{DESENVOLVIMENTO}

Inicialmente, foi utilizada uma câmera de fotografia no modo filmagem para verificar as imagens feitas pela câmera. Após a análise das filmagens, chegamos a conclusão que era possível o desenvolvimento desta tecnologia no Brasil. Testamos 03 câmeras de alta resolução e de ambiente industrial, sendo a que apresentou melhor performance foi a da marca Bosch. As figuras 4 e 5 ilustram este processo.
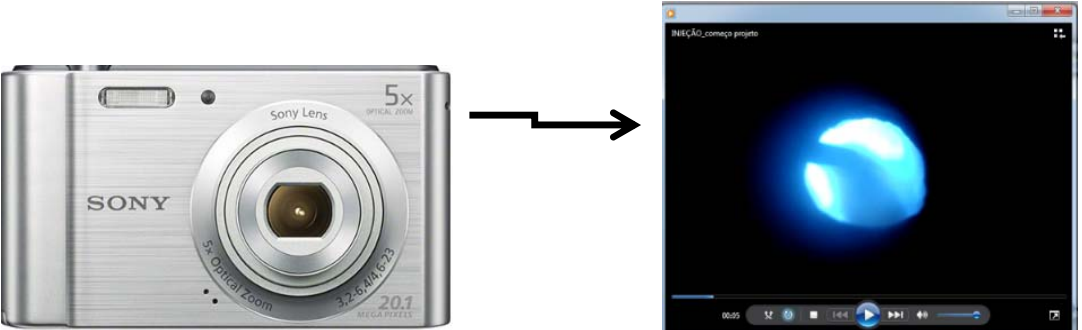

Figura 4 - Filmagem no interior do Alto Forno com uma câmera fotográfica

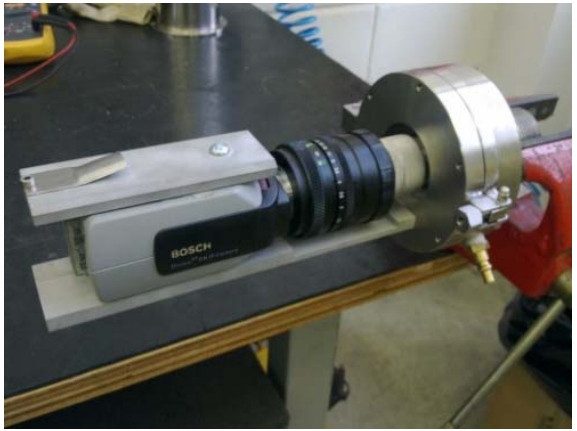

Figura 5 - Câmera Bosch utilizada na monitoração das ventaneiras do Alto Forno 3.

\subsection{Arquitetura do Sistema de Monitoração das Ventaneiras do AF-3}

SISTEMA DE MONITORAÇĀO DE VENTANEIRAS PARA ALTO FORNOS

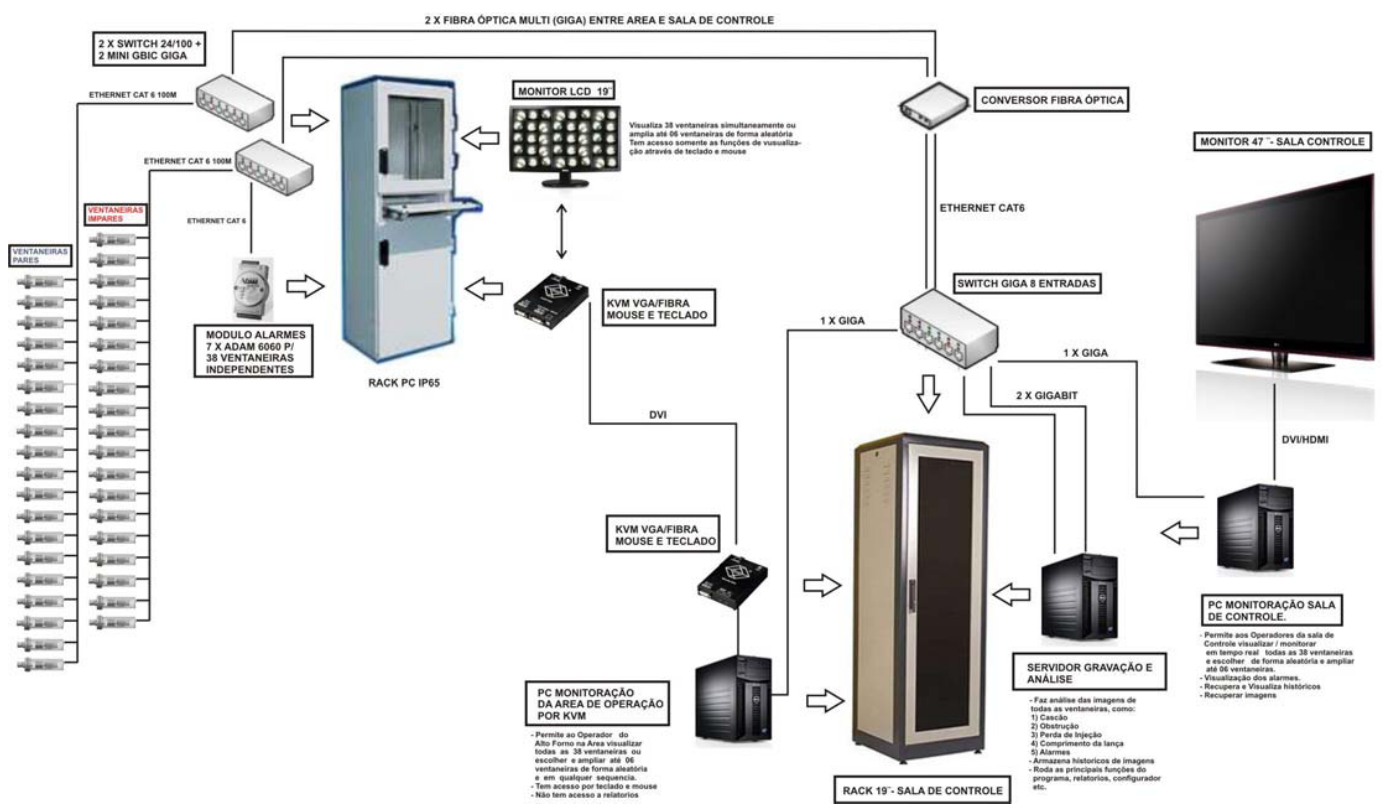

Figura 6 - Arquitetura do Sistema de Monitoração das Ventaneiras do AF-3. 


\subsection{Funcionamento do Sistema}

As imagens das câmeras instaladas nas ventaneiras são enviadas através de duas switchs por fibra óptica para a sala de controle do Alto Forno 3. Os sinais são então processados em dois servidores de imagem e um servidor de dados. O primeiro servidor de imagem é utilizado para a visualização das ventaneiras na sala de controle, sendo o segundo utilizado para a visualização na Sala de Corridas. No servidor de dados todas as imagens são processadas para visualização de alarmes, gráficos e gravação da filmagem de cada ventaneira. Todos os dados são gravados por uma semana para uma análise dos Staffs da operação do Alto Forno.

\subsection{Principais Recursos deste Sistema}

- Serviço de análise de imagens das ventaneiras ímpares e pares de 38 ventaneiras;

- Serviço de gravação de vídeos;

- Exibição de informações extras relacionadas aos alarmes;

- Visualizador de detalhe ampliado de até 6 ventaneiras (configuráveis).

- Gráficos de linha em razão do tempo;

- Gráficos de barra em razão do tempo;

- Visualizador de ocorrências;

- Tela de configuração geral do sistema

\subsection{Principais Telas Utilizadas na Monitoração das Ventaneiras}

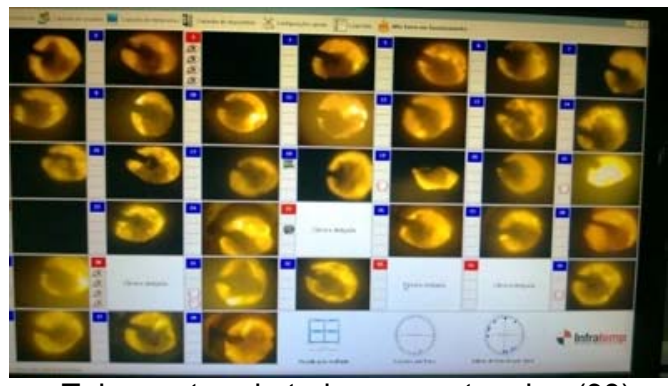

Tela mostrando todas as ventaneiras(38)

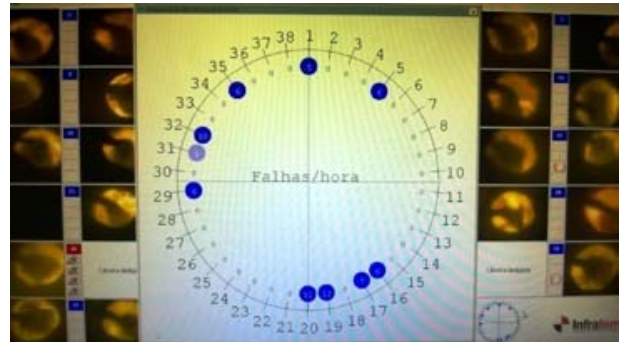

Tela de falhas de injeção das ventaneiras

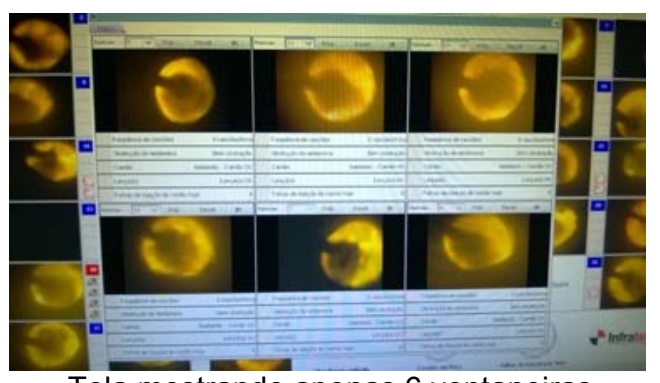

Tela mostrando apenas 6 ventaneiras

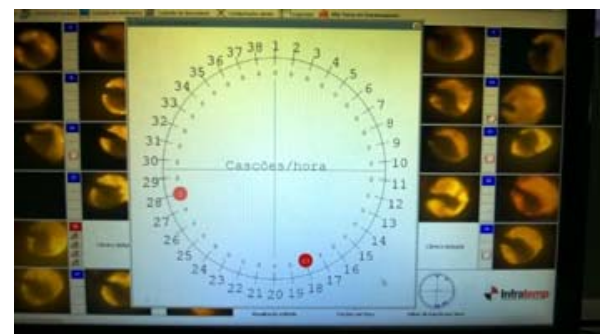

Tela de falhas de cascão das ventaneiras 


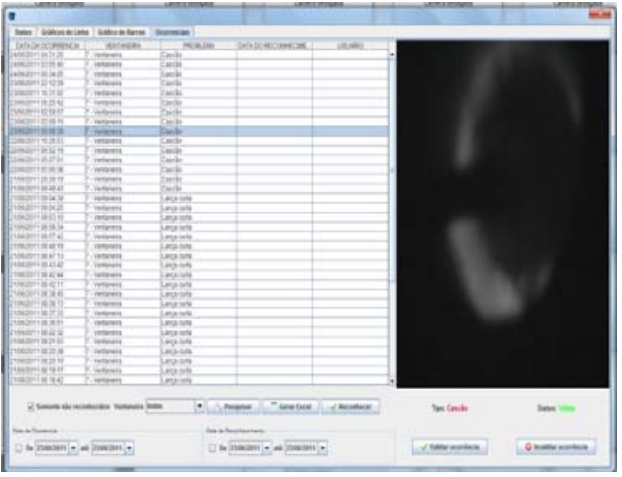

Tela de alarmes das ventaneiras

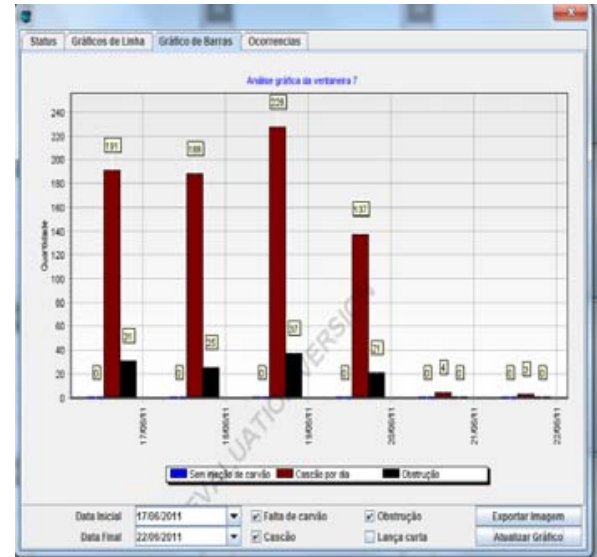

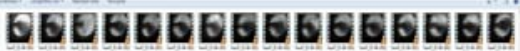

EEEEEEEEEEEEEEEE

EEEEEEEEEEEEEEEE

GEEEEEEESEEEEEEE

EEEEEEEEEEEEEEES

EEESEEEESEEESEES EEEEEEEEEEEEEE A

Arquivos de filmagem das ventaneiras

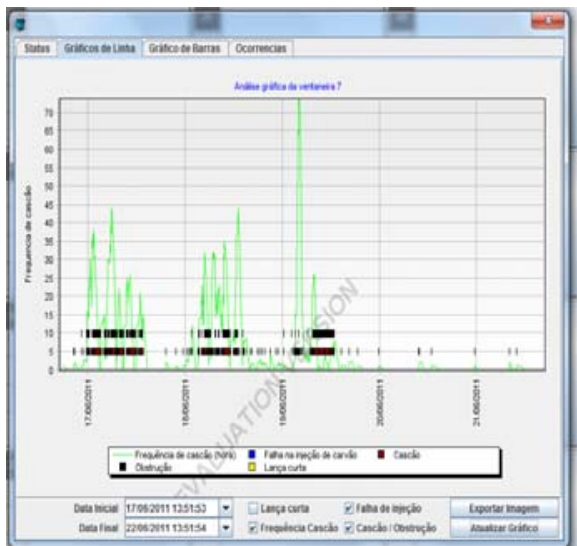

Tela para a verificação dos eventos ocorridos na injeção de carvão de $\mathrm{PCl}$ nas ventaneiras

Figura 7 - Principais telas utilizadas na monitoração das ventaneiras.

\section{PRINCIPAIS RESULTADOS OBTIDOS}

- Melhorar a inspeção das condições das ventaneiras, conforme mostrado na figura 7, 8 e 9;

- Evitar queima das ventaneiras por descentralização das lanças de injeção de carvão, conforme mostrado na figura 10 e 11;

- Reduzir/eliminar perda de produção por queima do Algaraviz, conforme mostrado na figura 12;

- Redução no tempo de solução dos problemas nas ventaneiras. 


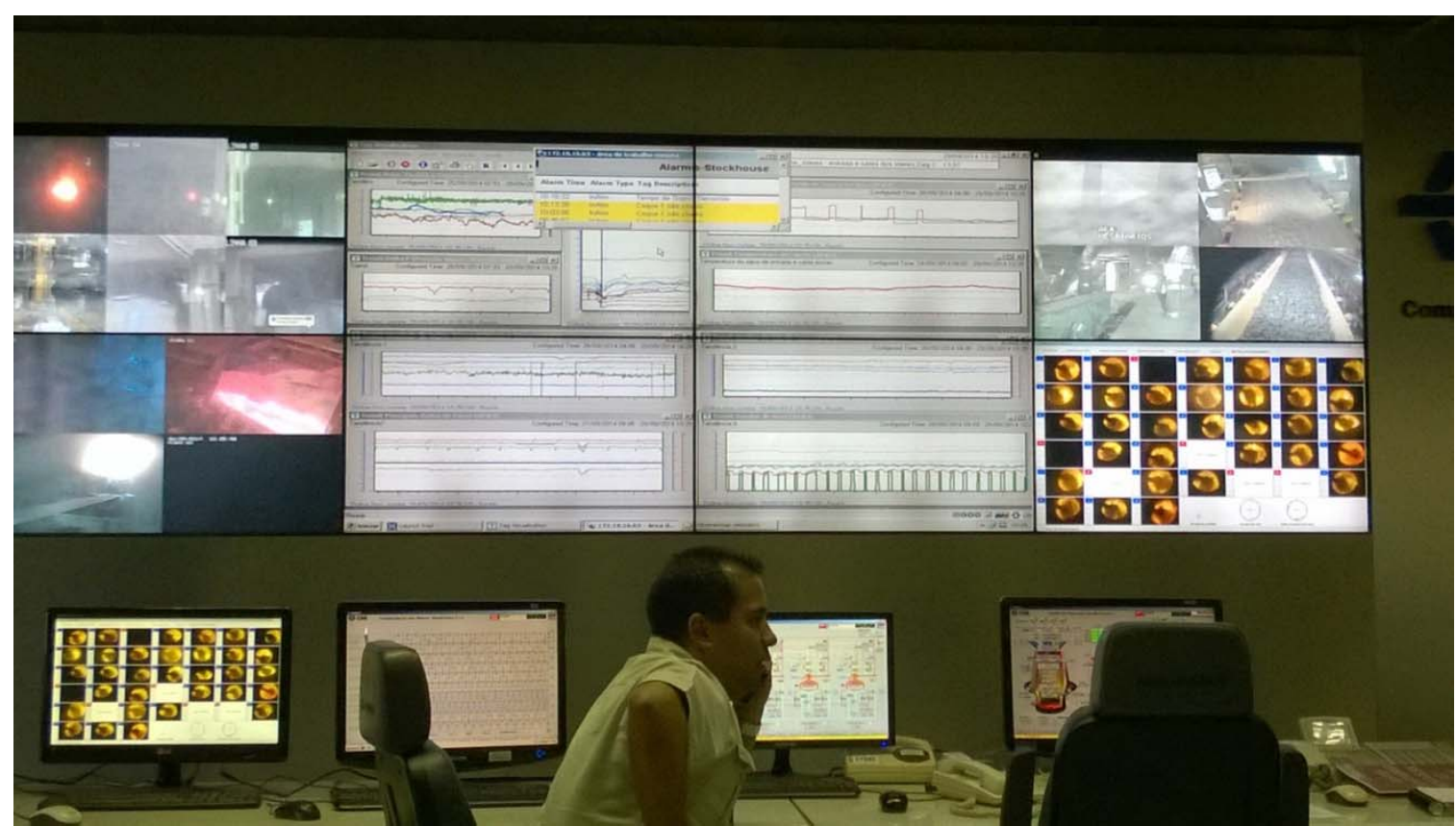

Figura 7 - Sala de Controle do Alto Forno 3 com as telas principais de controle

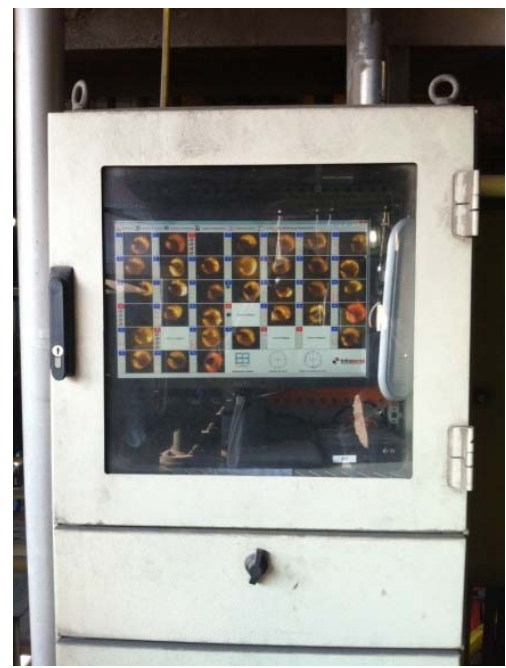

Figura 8 - Painel do sistema de monitoração das ventaneiras na Sala de Corridas

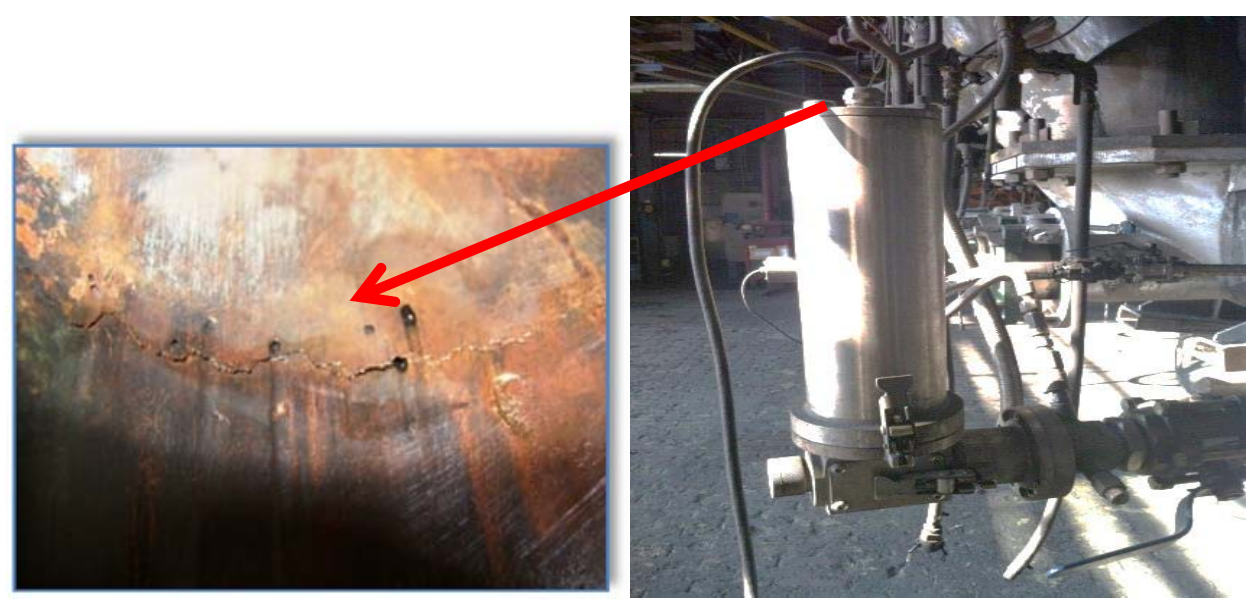

Figura 9 - Câmera acoplada na ventaneira 


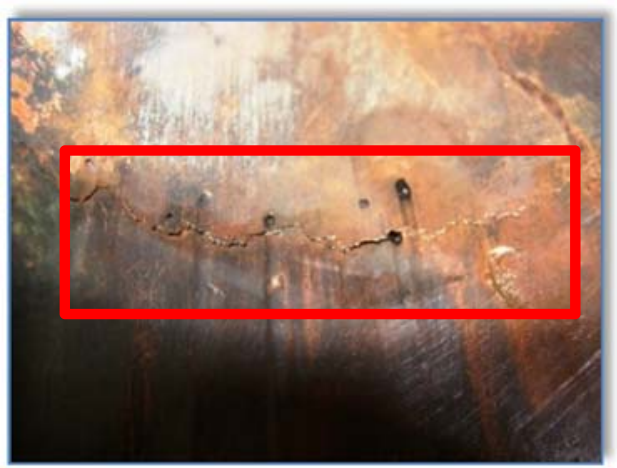

Figura 10 e 11 - Tela para verificação da centralização da lança de carvão pulverizado e ventaneira danificada por lança descentralizada.

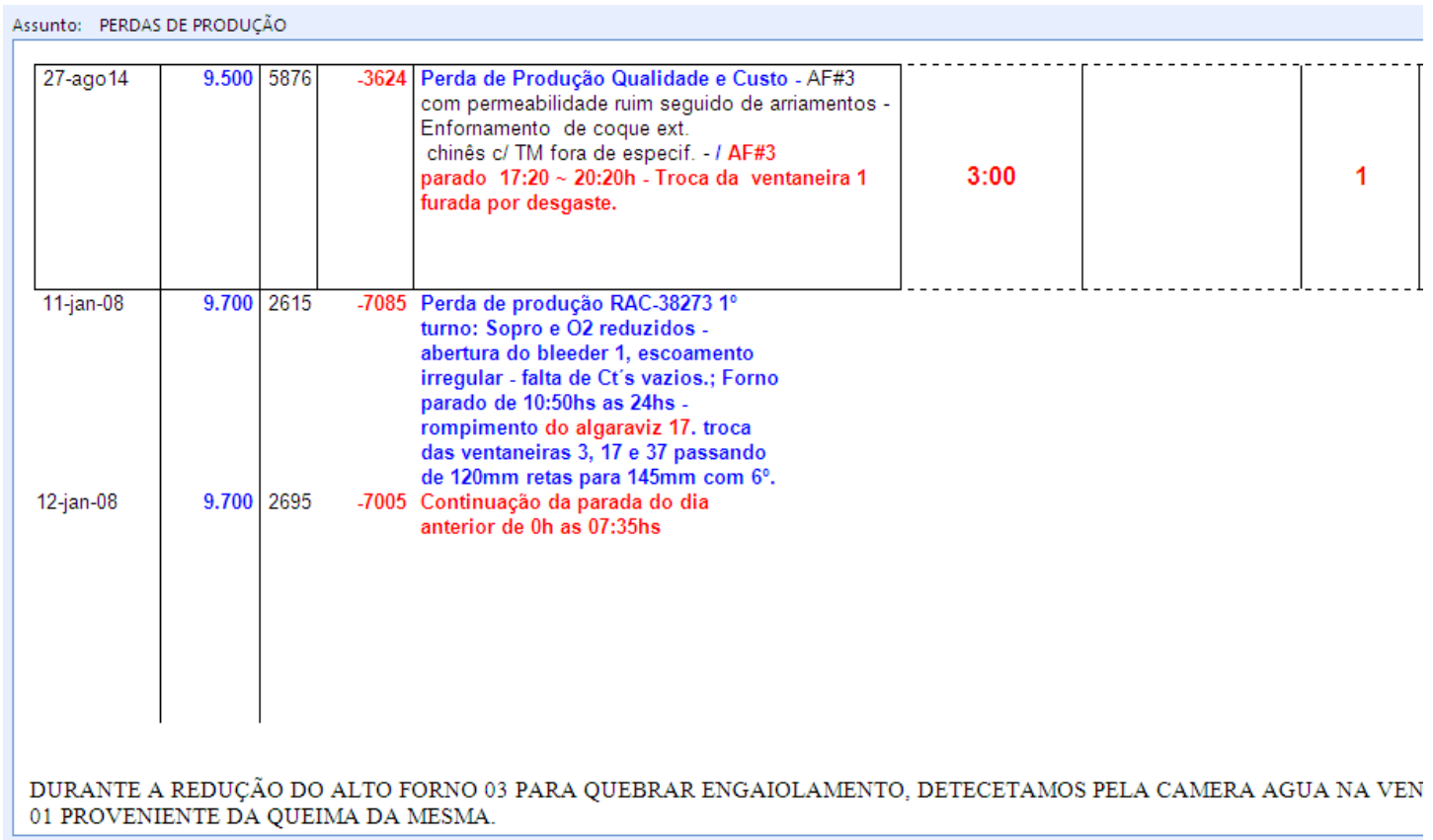

Figura 12 - Relatório de perda de produção de 17.714 toneladas no Alto Forno 3 devido ao entupimento do algaraviz, causando a explosão do tubo reto.

\section{CONCLUSÃO}

Com o uso deste Equipamento é possível inspecionar todas as ventaneiras em tempo real, antecipando correções de problemas muito antes do agravamento do mesmo. Única empresa na América Latina a utilizar esta tecnologia. Devido ao grande sucesso deste projeto, foi iniciado a implantação deste mesmo sistema no Alto Forno 2, com prazo de conclusão em Abril de 2015. 